\title{
Etiologia e perfil de sensibilidade antimicrobiana dos isolados bacterianos da mastite em pequenos ruminantes e concordância de técnicas empregadas no diagnóstico ${ }^{1}$
}

\author{
Rodolfo de M. Peixoto², Chirles A. de França², Aldo Ferreira de S. Júnior², \\ Josir Laine A. Veschi ${ }^{3}$ e Mateus M. da Costa ${ }^{2 *}$
}

\begin{abstract}
Peixoto R.M., França C.A., Souza Júnior A.F., Veschi J.L.A. \& Costa M.M. 2010. [Etiology and profile of antimicrobial sensitivity of bacteria from small ruminant mastitis and relationship of diagnostic techniques.] Etiologia e perfil de sensibilidade antimicrobiana dos isolados da mastite em pequenos ruminantes e concordância de técnicas empregadas no diagnóstico. Pesquisa Veterinária Brasileira 30(9):734-740. Campus Ciências Agrárias, Universidade Federal do Vale do São Francisco, Rodov. BR $407 \mathrm{Km}$ 12, Lote 543, Projeto de Irrigação Senador Nilo Coelho s/n, Petrolina, PE 56300-990, Brazil. E-mail: mateus.costa@univasf.edu.br

Mastitis is an inflammation of mammary gland, that are important in milking breed as well in meat ones. It is associated with serious reduction in milk production and quality, lambs weight gain reduction and mortality The goal of this work was determine the major etiologic agents of goat and sheep mastitis, as well as antimicrobial drug-resistance patterns and the agreement between two different diagnostic tools. We visit 25 goat, sheep, and goat and sheep farms in Pernambuco and Bahia State, and a total of 439 goats and 76 sheep milk samples were collected. To diagnose of small ruminant mastitis were compared two tests: Milk culture and California Mastitis Test (CMT). The bacterial drug-resistance pattern was determined by Kirby Bauer test. Staphylococcus spp. was the most frequent bacteria isolated from goat and sheep mastitis cases. Streptococcus spp., Corynebacterium spp. and gram-negative bacilli were isolated. It was possible to observe the high sensitivity to antimicrobial drugs in all tested bacteria, being the lower sensitivity percentage determined to nalidixic acid. Considering caprine mastitis diagnostic the comparative analysis between microbiologic culture and shown a concordance degree of $K=0,17$, although to ovine species these value was $K=0,22$. The use of CMT to subclinical mastitis diagnostic in goat and ewes must be associated to milk bacterial culture.
\end{abstract}

INDEX TERMS: Pathogens, antimicrobial sensitivity, diagnostic, mastitis.

RESUMO.- A mastite é a inflamação da glândula mamária que acomete raças de aptidão leiteira como também aquelas voltadas para produção de carne. Esta enfermidade ocasiona sérias alterações na produção de leite e na sua qualidade, redução no ganho de peso e mortalidade de cordeiros. O presente estudo teve por objetivo conhecer

\footnotetext{
${ }^{1}$ Recebido em 23 de fevereiro de 2010.

Aceito para publicação em 12 de abril de 2010.

2 Campus Ciências Agrárias, Universidade Federal do Vale do São Francisco, Rodov. BR $407 \mathrm{Km} \mathrm{12,} \mathrm{Lote} \mathrm{543,} \mathrm{Projeto} \mathrm{de} \mathrm{Irrigação} \mathrm{Sena-}$ dor Nilo Coelho s/n, Petrolina, PE 56300-990, Brasil. *Autor para correspondência: mateus.costa@ univasf.edu.br

3 Embrapa Semi- Árido, BR 428 Km 152, Zona Rural, Cx. Postal 23, Petrolina, PE 56302-970.
}

os principais agentes causadores de mastite em ovinos e caprinos, bem como a sua susceptibilidade aos agentes antimicrobianos, além de avaliar o grau de concordância entre testes diagnósticos. Foram visitadas 25 propriedades durante a realização do experimento, sendo criatórios de caprinos, ovinos e rebanhos mistos, nos estados de Pernambuco e Bahia. Coletou-se leite de 439 caprinos e 76 ovinos. Foi realizada lactocultura, o California Mastitis Test (CMT) e o teste de sensibilidade aos antimicrobianos. Além disso, determinou-se o grau de concordância entre os testes diagnósticos empregados. Foi constatada uma maior freqüência de Staphylococcus spp. nos casos de mastite em caprinos e ovinos, sendo observado ainda, isolados de Streptococcus spp., Corynebacterium spp. e bacilos gram negativos (BGN). Os isolados apresentaram 
alta sensibilidade aos antimicrobianos testados, sendo o menor percentual de sensibilidade observado para o ácido nalidíxico. Em relação ao diagnóstico da mastite caprina, a análise comparativa entre o exame microbiológico e o CMT demonstrou um grau de concordância igual a $K=0,17$, enquanto que para a espécie ovina, este valor foi de $K=0,22$. A utilização do CMT para o diagnóstico da mastite subclínica em cabras e ovelhas deverá ser associado à técnica da lactocultura.

TERMOS DE INDEXAÇÃO: Patógenos, sensibilidade antimicrobiana, diagnóstico, mastite.

\section{INTRODUÇÃO}

A produção de ovinos e caprinos no semi-árido é uma atividade relacionada à agricultura familiar, possuindo um forte compromisso com o desenvolvimento regional. No entanto, alguns problemas de ordem sanitária acarretam diminuição do potencial produtivo dos animais. Dentre estes problemas, destaca-se a mastite, que se caracteriza por um processo inflamatório da glândula mamária, provocado na sua maioria por microrganismos (Silva et al. 2001). Dentre as formas de mastite, a mastite clínica é facilmente diagnosticada por alterações no leite e no úbere, enquanto que a subclínica necessita de ferramentas diagnósticas para detecção do aumento da contagem de células somáticas (CCS) (Ladeira 1998, Anderson et al. 2004).

Segundo Contreras et al. (2007), a incidência da mastite clínica em pequenos ruminantes é inferior a $5 \%$, no entanto para a subclínica este percentual situa-se entre 5 e $30 \%$. Os principais gêneros bacterianos encontrados em casos de mastite em pequenos ruminantes são: Staphylococcus spp., Streptococcus spp., Corynebacterium spp., Pseudomonas sp., a Mannheimia haemolytica e algumas espécies de fungos, porém menos frequentes (Bergonier \& Berthelot 2003, Gonzalo et al. 2004, Contreras et al. 2007). Em ovinos, Staphylococcus aureus e Pasteurella haemolytica são responsáveis por $80 \%$ dos casos de mastite aguda, enquanto que Staphylococcus coagulase negativa (SCN) e Corynebacterium spp. são causadores da maioria dos casos de mastite subclínica (Vaz 1996).

Na mastite clínica, embora envolva os sinais clínicos característicos da enfermidade como dor, edema nos quartos afetados, o diagnóstico nem sempre é fácil. Da mesma forma, o diagnóstico da mastite subclínica é bastante complicado e envolve a detecção de células somáticas e o cultivo bacteriano (Klaas et al. 2004). Os métodos diretos empregados no diagnóstico da mastite baseiam-se na identificação do agente etiológico mediante a demonstração da presença de microrganismos nas amostras de leite encaminhadas aos laboratórios. Por outro lado, os testes indiretos se fundamentam em vários critérios de evolução de intensidade da reação inflamatória (Mota 2008).

Vários testes podem ser utilizados para determinar a contagem de CCS no leite, como o California Mastitis Test (CMT), o Wisconsin Mastitis Test (WMT) e a CECS (Contagem eletrônica de células somáticas) (Schroder \& Hamman
2005). A contagem de células somáticas constitui a base das técnicas de diagnóstico indireto das mastites em todas as espécies de ruminantes leiteiros (Mota 2008). A maioria das diferenças entre caprinos e ovinos que afetam o diagnóstico da mastite é relacionada ao CCS. Estas diferenças são, principalmente, em virtude da alta CCS em cabras não infectadas, o alto componente apócrino na secreção do leite e o elevado número de fatores não infecciosos que podem incrementar a contagem de células somáticas em cabras quando comparado com ovelhas (Paape et al. 2001).

Dessa forma é importante o conhecimento dos agentes causadores da mastite em ovinos e caprinos, bem como a determinação de sua sensibilidade aos agentes antimicrobianos, a fim de permitir o estabelecimento de uma terapia planejada com maiores chances de sucesso. Além disso, fazse necessário estudo acerca da correlação entre técnicas diagnósticas voltadas para a mastite, principalmente na espécie caprina em decorrência das particularidades encontradas na fisiologia da glândula mamária nesta espécie.

\section{MATERIAL E MÉTODOS}

Foram visitadas 25 propriedades, sendo 17 criatórios de caprinos, seis de ovinos e dois rebanhos mistos, nos estados de Pernambuco e Bahia. As criações de caprinos eram destinadas à produção de leite, com animais de diferentes idades, estágios de lactação, sistemas de criação, com o emprego da ordenha manual. Os ovinos eram criados para a produção de carne, sendo a amostragem constituída por fêmeas recémparidas, em diferentes idades, raças e sistemas de criação. Coletou-se leite de 439 caprinos e 76 ovinos, perfazendo um total de 515 animais e 1.030 metades mamárias.

Para detecção da mastite subclínica foi utilizado o teste de CMT. Este foi realizado conforme descrições de Schalm \& Noorlander (1957). O leite de cabras e ovelhas foi coletado após a lavagem dos tetos, sendo que os três primeiros jatos foram desprezados. O leite foi então misturado ao reativo, contendo detergente e púrpura de bromocresol em uma superfície plana. Em seguida foi observada a formação de grumos, a qual se apresentava com maior ou menor intensidade de acordo com a quantidade de células somáticas. Para a espécie caprina a positividade foi considerada a partir do escore $\geq 2+$, enquanto que na espécie ovina considerou-se o escore $\geq 1+$.

$\mathrm{O}$ isolamento bacteriano foi realizado a partir de leite coletado antes da ordenha, após lavagem e cuidadosa anti-sepsia dos tetos com álcool a $70 \%$, sendo que os três primeiros jatos foram desprezados. O leite foi coletado diretamente em frascos estéreis, previamente identificados e colocados em caixas isotérmicas com gelo e encaminhados imediatamente ao laboratório de Microbiologia e Imunologia da Universidade Federal do Vale do São Francisco (UNIVASF) para processamento.

Volumes de $10 \mu \mathrm{l}$ de cada amostra foram semeados com alça calibrada em cada quadrante de uma placa de Blood Agar Base acrescido de $5 \%$ de sangue desfibrinado de carneiro. Assim, foram consideradas positivas as placas que apresentavam uma colônia hemolítica e/ou aquelas que continham quatro colônias não hemolíticas ou mais com as mesmas características morfológicas (Anderson et al. 1991). As bactérias foram identificadas de acordo com características morfológicas, bioquímicas e tintoriais, conforme descrito por Quinn et al. 
(1994). Para identificação dos isolados pertencentes ao gênero Staphylococcus foram realizados testes bioquímicos da coagulase, DNAse, utilização da glicose semi-sólida e manitol semi-sólido, além dos meios purple ágar base, esculina e urease (Holt et al. 1994).

O perfil de sensibilidade dos microrganismos foi determinado pelo método de difusão em disco Kirby-Bauer modificado (CLSI 2006). Os isolados foram semeados em caldo Müller Hinton e incubados a $37^{\circ} \mathrm{C}$ até obtenção de turvação conforme a escala 0,5 de Mac Farland. Com auxílio de um swab, os isolados foram semeados em placas de Petri contendo ágar Müller Hinton. Logo após foram aplicados os discos impregnados com as drogas antimicrobianas que incluíram: gentamicina $(10 \mu \mathrm{g})$, estreptomicina $(10 \mu \mathrm{g})$, neomicina $(30 \mu \mathrm{g})$, ceftriaxona $(30 \mu \mathrm{g})$, eritromicina $(15 \mu \mathrm{g})$, lincomicina $(02 \mu \mathrm{g})$, oxacilina $(01 \mu \mathrm{g})$, ampicilina $(10 \mu \mathrm{g})$, amoxicilina $(10 \mu \mathrm{g})$, ácido nalidíxico $(30 \mu \mathrm{g})$, ciprofloxacina $(05 \mu \mathrm{g})$, norfloxacina $(10 \mu \mathrm{g})$, enrofloxacina $(5 \mu \mathrm{g})$, tetraciclina $(30 \mu \mathrm{g})$, doxiciclina $(30 \mu \mathrm{g})$ e rifampicina $(05 \mu \mathrm{g})$. As placas foram incubadas em estufa por $24 \mathrm{~h}$ a $37^{\circ} \mathrm{C}$. Após a leitura dos halos foi determinado o perfil de sensibilidade e resistência dos isolados.

Empregou-se a técnica de estatística descritiva por meio da distribuição das frequências relativa e absoluta para os achados microbiológicos. Para o cálculo do índice Kappa e da concordância entre os testes utilizou-se o WIN EPISCOPE 2.0 (Thrusfield 2004).

\section{RESULTADOS}

Em relação ao diagnóstico indireto da mastite caprina, das 816 amostras negativas no CMT, 687 (84,2\%) também foram negativas no exame microbiológico. Levando-se em consideração a positividade a partir do escore $\geq 1+$, observou-se que das 119 amostras positivas no CMT, 75 (63,0\%) foram negativas no exame microbiológico. Para a positividade ao escore 2 ou $3+$, das 62 amostras positivas no CMT, $34(54,8 \%)$ foram negativas no exame microbiológico. Os valores de concordância entre o exame microbiológico e o CMT foram iguais a 78,6 e $81,4 \%$ para a positividade partir dos escores $\geq 1+e \geq 2+$, respectivamente. O índice Kappa foi igual a $K=0,17$, indicando uma concordância pobre.
Para a espécie ovina, observou-se que das 138 amostras negativas no CMT, 101 (73,2\%) também foram negativas no exame microbiológico. A partir do escore $\geq 1+$, das 14 amostras positivas no CMT, quatro $(28,6 \%)$ foram negativas no exame microbiológico. A concordância entre o exame microbiológico e o CMT a partir do escore $\geq 1+$ ou $\geq 2+$ foi de $73 \%$, sendo o índice Kappa igual a $K=0,22$, sendo indicativo de uma concordância fraca.

Os principais microrganismos isolados das amostras de leite são listados no Quadro 1. No exame microbiológico do leite, na espécie caprina, das 878 amostras de leite analisadas, observou-se que $17,9 \%(n=157)$ foram positivas no exame microbiológico. Nesta espécie animal foram isolados Staphylococcus spp. (29,9\%), Staphylococcus aureus (16,9\%), Staphylococcus hyicus $(11,7 \%)$, Staphylococcus caprae $(7,8 \%)$, Staphylococcus intermedius $(7,1 \%)$, Staphylococcus epidermidis (6,5\%), Staphylococcus simulans (1,9\%), Micrococcus spp. $(9,7 \%)$, Streptococcus spp. $(2,6 \%)$, Corynebacterium spp. $(1,9 \%)$ e enterobactérias $(3,9 \%)$. Na espécie ovina, das 152 amostras de leite analisadas, observou-se uma positividade de $30,9 \%(n=47)$, sendo isolados Staphylococcus spp. (28,6\%), Staphylococcus aureus (14,3\%), Staphylococcus hyicus (10,7\%), Staphylococcus intermedius (16,1\%), Staphylococcus epidermidis (12,5\%), Staphylococcus saprophyticus $(1,8 \%)$, Streptococcus spp. (3,6\%), Corynebacterium spp. $(5,4 \%)$ e enterobactérias $(7,1 \%)$.

O perfil de sensibilidade antimicrobiana dos isolados obtidos de casos de mastite caprina e ovina estão na Fig.1. Foram observados os seguintes percentuais de sensibilidade: aminoglicosídeos (gentamicina $=92,39 \%$, estreptomicina $=75,00 \%$ e neomicina $=56,74 \%$ ); macrolídeo (eritromicina $=83,25 \%$ ); lincosamida (lincomicina $=$ $82,99 \%$ ); beta-lactâmicos (ceftriaxona $=81,60 \%$, oxacilina $=84,85 \%$, ampicilina $=72,28 \%$ e amoxicilina $=61,49 \%)$; quinolonas (enrofloxacina $=89,35 \%$, norfloxacina $=84,81 \%$, ciprofloxacina $=87,82 \%$ e ácido nalidíxico $=21,74 \%$ ); tetraciclinas (doxiciclina $=95,11 \%$ e tetraciclina $=87,43 \%$ ) e rifampicina $=81,42 \%$.

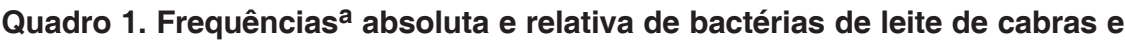
ovelhas nos estados de Pernambuco e Bahia, 2009

\begin{tabular}{lccccccc}
\hline & \multicolumn{2}{c}{ Caprinos } & \multicolumn{2}{c}{ Ovinos } & \multicolumn{2}{c}{ Caprino + Ovino } \\
\cline { 2 - 6 } Bactéria isolada & FA & FR & FA & FR & FA & FR \\
\hline Staphylococcus spp. & 46 & 29,9 & 16 & 28,6 & 62 & 29,5 \\
Staphylococcus aureus & 26 & 16,9 & 08 & 14,3 & 34 & 16,2 \\
Staphylococcus hyicus & 18 & 11,7 & 06 & 10,7 & 24 & 11,4 \\
Staphylococcus intermedius & 11 & 7,1 & 09 & 16,1 & 20 & 9,5 \\
Staphylococcus epidermidis & 10 & 6,5 & 07 & 12,5 & 17 & 8,1 \\
Staphylococcus caprae & 12 & 7,8 & - & - & 12 & 5,7 \\
Staphylococcus simulans & 03 & 1,9 & - & - & 03 & 1,4 \\
Staphylococcus saprophyticus & - & - & 01 & 1,8 & 01 & 0,5 \\
Micrococcus spp. & 15 & 9,7 & - & - & 15 & 7,1 \\
Streptococcus spp. & 04 & 2,6 & 2 & 3,6 & 06 & 2,9 \\
Corynebacterium spp. & 03 & 1,9 & 3 & 5,4 & 06 & 2,9 \\
Enterobactérias & 06 & 3,9 & 4 & 7,1 & 10 & 4,8 \\
Total & 154 & 100,0 & 56 & 100,0 & 210 & 100,0 \\
\hline
\end{tabular}

$\bar{a}$ FA = Frequência absoluta; FR= Frequência relativa. 


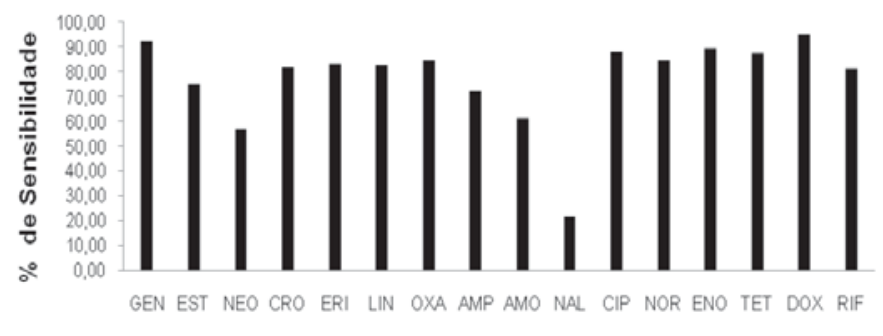

Antimicrobianos

Fig.1. Percentual de sensibilidade aos antimicrobianos de isolados de mastite ovina e caprina. GEN (gentamicina), EST (estreptomicina), NEO (neomicina), CRO (ceftriaxona), ERI (eritromicina), LIN (lincomicina), OXA (oxacilina), AMP (ampicilina), AMO (amoxicilina), NAL (ácido nalidíxico), CIP (ciprofloxacina), NOR (norfloxacina), ENO (enrofloxacina), TET (tetraciclina), DOX (doxiciclina) e RIF (rifampicina).

\section{DISCUSSÃO}

Quando se relacionou as técnicas empregadas no diagnóstico da mastite em cabras, observou-se uma maior concordância entre o exame microbiológico e o CMT para o limiar $\geq 2+$. Pêssoa et al. (1999) encontraram os seguintes valores de concordância para os limiares $\geq 1+e \geq 2+, 59,85$ e $71,43 \%$, respectivamente. Em decorrência do maior número de células somáticas no leite de fêmeas caprinas, estudos apontam uma maior confiabilidade do CMT quanto à sua sensibilidade a partir do nível de 2+. Contudo, vários trabalhos demonstram uma ampla variação para os valores de concordância entre a positividade no CMT e a lactocultura (Contreras et al. 1996, Bezerra et al. 2006, Almeida 2009). Tonin \& Nader Filho (2005), observaram que a concordância entre o CMT e o exame microbiológico do leite para o escore traços na espécie caprina foi o mais elevado, denotando a importância de se considerar qualquer grau de reatividade ao CMT, principalmente quando se pretende realizar a triagem de casos de mastite subclínica em cabras.

Na espécie ovina, não foi observada variação nos valores de concordância entre o exame microbiológico e o CMT para os limiares $\geq 1+e \geq 2+$, sugerindo que o limiar de $\geq 1+$ pode ser empregado. Avaliando amostras de leite de fêmeas ovinas, Domingues et al. (2006) observaram que das 88 amostras positivas ao teste CMT, 14 (16,0\%) apresentaram resultados negativos no cultivo microbiológico. $O$ uso do CMT também apresenta limitações quando aplicado na espécie ovina, já que o teste foi inicialmente desenvolvido para espécie bovina, apresentando melhor conjunto de sensibilidade e especificidade quando empregado nesta espécie (Maisi et al. 1987). Nunes et al. (2008) recomendam o escore 1+ do CMT para a discriminação entre as fêmeas ovinas positivas e negativas para a mastite subclínica, considerando que este escore apresenta boa especificidade sem comprometer demasiadamente a sensibilidade.

Os microrganismos mais frequentes neste estudo foram os Staphylococcus spp. o que corrobora com vários outros estudos sobre a etiologia da mastite caprina e ovi- na no Brasil (Mota et al. 2000, Langoni et al. 2006, Coutinho et al. 2006, Domingues et al. 2006, Almeida 2009, Bolsanello et at. 2009). O isolamento de microrganismos do gênero Staphylococcus reforça a sua importância na etiologia de mastite subclínica (Contreras et al. 2007).

Observou-se neste estudo, elevada frequência da espécie Staphylococcus aureus (16,2\%). Na Nigéria, Ameh \& Tari (2000) evidenciaram maior frequência de S. aureus (37\%) em rebanhos de cabras leiteiras em contraste com a presença dos SCN (6\%). O isolamento de $S$. aureus demonstra a necessidade da implantação de medidas sanitárias visando minimizar os danos causados por esta espécie. Além disso, trata-se de um agente relevante para a saúde pública, principalmente devido a presença de toxinas (Fagundes \& Oliveira 2004). De acordo com Freitas et al. (2004), vários trabalhos foram realizados sobre este microrganismo, contudo outros estudos são necessários para se compreender melhor o envolvimento desta bactéria na etiologia de doenças que acometem humanos e animais, desde o tecido cutâneo até infecções sistêmicas.

Neste trabalho, $12,5 \%$ dos isolados provenientes do leite de ovelhas pertenciam à espécie $S$. epidermidis. De acordo com Bergonier et al. (2003), dentre as espécies de SCN mais prevalentes em ovelhas tem-se em ordem decrescente de importância o Staphylococcus epidermidis, S. xylosus, S. chromogenes e S. simulans. Com relação à espécie caprina, 7,8\% dos isolados eram Staphylococcus caprae, sendo esta considerada a espécie de maior ocorrência dentre os SCN (Bergonier et al. 2003).

Neste trabalho também foram isolados bacilos gram negativos $(4,76 \%)$ pertencentes à família Enterobacteriaceae. $\mathrm{O}$ isolamento de microrganismos da família Enterobacteriaceae associada à mastite clínica é um achado comum. As enterobactérias são consideradas importantes agentes das mastites ambientais (Prestes et al. 2002). Ribeiro et al. (2007) relataram a primeira ocorrência de um caso de mastite gangrenosa causada por três agentes infecciosos distintos em uma fêmea da espécie caprina, na qual foi observado um quadro clínico com alterações sistêmicas, sendo constatada a presença de Staphylococcus aureus, Clostridium perfringens e E. coli.

Observou-se alta frequência de isolados sensíveis aos antimicrobianos avaliados neste trabalho, sendo o menor percentual de sensibilidade para o ácido nalidíxico. Poucos são os trabalhos que têm como resultados a identificação de cepas com pouca sensibilidade ao grupo das quinolonas, sendo relatado o desenvolvimento de resistência apenas em casos experimentais, depois de repetidas passagens, aparecendo de forma lenta e gradual (Scheer 1987). Alguns estudos realizados no Brasil demonstraram a presença de sensibilidade entre os diferentes patógenos isolados de casos de mastite em caprinos e ovinos (Silva et al. 2004, Coutinho et al. 2006, Almeida 2009), principalmente para a gentamicina (Mota et al. 2000, Langoni et al. 2006, Domingues et al. 2006).

Os grupos de antimicrobianos utilizados na terapia humana e veterinária são os mesmos e com isto a resistên- 
cia cruzada pode ocorrer. Desta forma, estes patógenos podem representar um risco à saúde pública, especialmente pelo consumo de queijo cru (Contreras et al. 2007). Aliado a isto, o uso indiscriminado de antibióticos pode favorecer a seleção de microrganismos resistentes e tem se tornado um problema de saúde pública. A detecção de cepas de $S$. aureus resistentes aos aminoglicosídeos deve ser considerada uma preocupação para saúde pública, dado ao mecanismo similar para cepas isoladas em humanos (Goni et al. 2004).

Lollai et al. (2008) analisaram o perfil e a evolução da resistência antimicrobiana de patógenos da mastite ovina entre o período de 1995 e 2004, identificando que a resistência de Staphylococcus spp. a penicilina foi menor do que o relatado em outros estudos $(4,1 \%$ de cepas resistentes de $S$. aureus e 15,3\% para Staphylococcus coagulase negativa). Índices maiores de resistência foram observados para aminoglicosídeos. Os autores concluíram que o perfil encontrado parece confirmar a menor resistência dos patógenos de ovinos, quando comparados aos de origem bovina.

Os resultados demonstram que na caprinocultura leiteira do sertão da Bahia e Pernambuco, os principais patógenos envolvidos em casos de mastite subclínica são aqueles pertencentes ao gênero Staphylococcus spp. Os rebanhos ovinos voltados para produção de carne também demonstram susceptibilidade à mastite. Os isolados bacterianos obtidos de casos de mastite deste estudo apresentam um elevado percentual de sensibilidade para a maioria dos grupos antimicrobianos. Entretanto, demonstra-se baixa sensibilidade para o ácido nalidíxico. A utilização do CMT para o diagnóstico da mastite subclínica em cabras e ovelhas deverá sempre ser associado à técnica da lactocultura.

Agradecimentos.- À FACEPE pela concessão da bolsa de pós-graduação (R.M. Peixoto), a FAPESB pela concessão da bolsa de iniciação científica (A.F. Souza Júnior) e ao IDR sisal pelo apoio financeiro e cedência das instalações.

\section{REFERÊNCIAS}

Almeida J.F. 2009. Agentes infecciosos causadores de mastite e parâmetros físico-químicos na qualidade do leite de cabra in natura. Tese de Doutorado em Higiene Veterinária e Processamento Tecnológico de Produtos de Origem Animal, Faculdade de Veterinária, Universidade Federal Fluminense, Rio de Janeiro, RJ. 106p.

Ameh M.J.A. \& Tari I.S. 2000. Observations on the prevalence of caprine mastitis in relation to predisposing factors in Maiduguri. Small Rumin. Res. 35:1-5.

Anderson K.L., Wesen D.P. \& Fetrow J. 1991. Influence of inoculum volume in diagnosis of environmental mastitis from clinical quarters. J. Vet. Diagn. Invest. 3:165-167.

Anderson D.E., Hull B.H. \& Pugh D.G. 2004. Enfermidades da glândula mamária, p.379-399. In: Pugh D.G. (Ed.), Clínica de Ovinos e Caprinos. Roca, São Paulo.

Bergonier D. \& Berthelot X. 2003. New advances in epizootiology and control of ewe mastitis. Livest. Prod. Sci. 79:1-16.

Bergonier D., De Crémoux R., Rupp R., Lagriffoul G. \& Berthelot X. 2003. Mastitis of dairy small ruminants. Vet. Res. 34:689-716.
Bezerra A.C.A., Feijó F.M.C., Silva J.S. \& Avelino D.B. 2006. Relação entre o "California Mastitis Test" e os agentes microbianos de mastites em caprinos no estado do Rio Grande do Norte. Revta Bras. Med. Vet. 28(4):160-165.

Bolsanello R.X., Hartman M., Domingues P.F., Mello Júnior A.Z. \& Langoni H. 2009. Etiologia da mastite em ovelhas Bergamácia submetidas à ordenha mecânica, criadas em propriedade de Botucatu, SP. Vet. Zootec. 16(1):221-227.

CLSI 2006. Methods for dilution antimicrobial susceptibility tests for bacteria that grow aerobically: Approved standards. Document CLSI M7-A7, CLSI, Clinical and Laboratory Standard Institute, Wayne, Pennsylvania.

Contreras A. 1996. Factors affecting milk somatic-cell counts in murciano-granadina goats, p.173-176. In: Rubino R. (Ed.), Somatic Cells and Milk of Small Ruminants. Wageningen Academic Publishers, Wageningen.

Contreras A., Sierra D., Sánchez A., Corrales J.C., Marco J.C., Paape M.J. \& Gonzalo C. 2007. Mastitis in small ruminants. Small Rumin. Res. 68:145-153.

Coutinho D.A., Costa J.N., Ribeiro M.G. \& Torres J.A. 2006. Etiologia e sensibilidade antimicrobiana in vitro de bactérias isoladas de oveIhas da raça Santa Inês com mastite subclínica. Revta Bras. Saúde Prod. Anim. 7(2):139-151.

Domingues P.F., Lucheis S.B., Serrão L.S., Fernandes L.S., Contente A.P.A., Martins E.C.V. \& Langoni H. 2006. Etiologia e sensibilidade bacteriana da mastite subclínica em ovelhas da raça Santa Inês. Ars Vet. 22(2):146-152.

Fagundes H. \& Oliveira C.A.F. 2004. Infecções intramamárias causadas por Staphylococcus aureus e suas implicações em saúde pública. Ciência Rural 34(4):1315-1320.

Freitas M.F.L., Leal Balbino T.C., Mota R.A. \& Stamford T.L.M. 2004. Exotoxinas estafilocócicas. Ciênc. Vet. Tróp. 7(2/3):63-74.

Goni P.,Vergara Y., Ruiz J., Albizu I.,Vila J. \& Gomez-Lus R. 2004. Antibiotic resistance and epidemiological typing of Staphylococcus aureus strains from ovine and rabbit mastitis. Int. J. Antimicrob. Agents 23:268-272.

Gonzalo C., Tardáguila J.A., De La Fuente L.F. \& San Primitivo F. 2004. Effects of selective and complete dry therapy on prevalence of intramammary infection and on milk yield in the subsequent lactation in dairy ewes. J. Dairy Res. 71:33-38.

Holt J.G. 1994. Bergey's Manual of Determinative Bacteriology. Williams and Wilkins, Baltimore. 787p.

Klaas I.C., Enevoldsen C., Vaarst M. \& Houeh H. 2004. Systematic clinical examinations for identification of lattent udder health types in Danish dairy herds. J. Dairy Sci. 87:1217-1228.

Ladeira S.R.L. 1998. Mastite ovina, p.261-264. In: Riet-Correa F., Schild A.L. \& Méndez M.D.C. (Eds), Doenças de Ruminantes e Eqüinos. Ed. Universitária/UFPel, Pelotas.

Langoni H., Domingues P.F. \& Baldini S. 2006. Mastite caprina: seus agentes e sensibilidade frente a antimicrobianos. Revta Bras. Ciênc. Vet. 13(1):51-54.

Lollai S.A., Ziccheddu M., Maurob C.D., Manunta D., Nuddab A. \& Leori G. 2008. Profile and evolution of antimicrobial resistence of ovine mastitis pathogens. Small Rumin. Res. 74:249-254.

Maisi P., Juntila J., Seppanen J. 1987. Detection of subclinical mastitis in ewes. Brit. Vet. J. 143:402-409.

Mota R.A. 2008. Aspectos epidemiológicos, diagnóstico e controle das mastites em caprinos e ovinos. Tecnol. Ciênc. Agropec. 2(3):57-61.

Mota R.A., De Castro F.J.C., Da Silva L.B.G. \& Oliveira A.A.F. 2000. Etiologia e sensibilidade a antimicrobianos in vitro das bactérias isoladas do leite de cabras com mastite procedentes da Região Metropolitana do Recife, Pernambuco, Brasil. Hora Vet. 19(114)26-29.

Nunes G.R., Blagitz M.G., Freitas C.B., Souza F.N., Ricciardi M., 
Stricagnolo C.R., Sanches B.G.S., Azedo M.R., Sucupira M.C.A. \& Della Libera AM.M.P. 2008. Avaliação de indicadores inflamatórios no diagnóstico da mamite ovina. Arqs Inst. Biológico, São Paulo, 75(3):271-278.

Paape M.J., Poutrel B., Contreras A., Marco J.C. \& Capuco A.V. 2001. Milk somatic cells and lactation in small ruminants. J. Dairy Sci. 84:237-244.

Pêssoa A.L.P., Lima Júnior A.D. \& Mota R.A. 1999. Estudo do limiar de células somáticas no leite de cabras na região metropolitana de Recife e agreste de Pernambuco. Ciênc. Vet. Tróp. 2(2):100-107.

Prestes D.S., Filappi A. \& Cecim M. 2002. Susceptibilidade à mastite: fatores que a influenciam: uma revisão. Revta FZVA, Uruguaiana, 9(1):118-132.

Quinn P.J., Carter, M.E., Markey B. \& Carter G.R. 1994. Clinical Veterinary Microbiology. Wolfe, London. 648p.

Ribeiro M.G., Lara G.H.B., Bicudo S.D., Souza A.V.G., Salerno T., Siqueira A.K. \& Geraldo J.S. 2007. An unusual gangrenous goat mastitis caused by Staphylococcus aureus, Clostridium perfringens and Escherichia coli co-infection. Arq. Bras. Med. Vet. Zootec. 59(3):810-812.

Schalm O.W. \& Noorlander D.O. 1957. Experiments and observations leading to development of the California Mastitis Test. J. Am. Vet. Med. Assoc. 130(5):199-207.

Scheer M. 1987. Concetraciones de sustancia activa en el suero y em los tejidos después de administración oral y parenteral de Baytril. Notícias Méd. Vet. 2:104-118.

Schroder A.C. \& Hamman J. 2005. The influence of technical factors on differential cell counts in milk. J. Dairy Res. 72:153-158.

Silva E.R., Araújo A.M., Alves F.S.F., Pinheiro R.R. \& Saukas T.N. 2001. Associação entre o California Mastitis Test e a Contagem de Células Somáticas na avaliação da saúde da glândula mamária caprina. Braz. J. Vet. Res. Anim. Sci. 38:46-48.

Silva E.R., Siqueira A.P., Martins J.C.D., Ferreira W.P.B. \& Silva N. 2004. Identification and in vitro antimicrobial susceptibility of Staphylococcus species isolated from goat mastitis in the Northeast of Brazil. Small Rumin. Res. 55:45-49.

Thrusfield M.V. 2004. Epidemiologia Veterinária. 2ª ed. Roca, São Paulo. $556 \mathrm{p}$.

Tonin F.B. \& Nader Filho A. 2005. Correlação entre o "California Mastitis Test" e o exame bateriológico no leite de cabras. Ars Vet. 21:155159.

Vaz A.K. 1996. Mastite em ovinos. Hora Vet. 93:75-78. 